\title{
Laicidad y ministerios en el cristianismo primitivo. A propósito de Un solo corpo de Romano Penna
}

\author{
Laity and Ministries in Early Christianity. \\ About Romano Penna's «Un solo corpo»
}

RICARDO SANJURJO OTERO

Instituto Teológico Compostelano

ORCID: https://orcid.org/0000-0003-1375-7064 | rsanjurjo@itcdesantiago.org

Fecha de recepción: 30/6/2021

Fecha de aceptación: 20/7/2021

https://doi.org/10.52039/seminarios.v66i228.449

RESUMEN: La perspectiva que adopta Romano Penna en su última obra acerca del sacerdocio y el laicado en los orígenes de la Iglesia aporta una novedad interesante al situar la cuestión del nacimiento de los ministerios eclesiales (y del ministerio sacerdotal en concreto) en el marco más amplio de la identidad de la Iglesia misma. Esto lo convierte en una excelente aportación no sólo para el estudio de los orígenes del cristianismo, sino también para iluminar la actualidad eclesial. La presente nota quiere entrar en diálogo con la obra para profundizar en algunos de sus aspectos más significativos.

PALABRAS ClaVE: Eclesiología; Iglesia primitiva; Sacerdocio.

ABSTRACT: The perspective Romano Penna adopts in his latest work on the priesthood and the laity in the origins of the Church brings an interesting novelty by placing the question of the birth of ecclesial ministries (and of the priestly ministry in particular) in the broader framework of the identity of the Church itself. This makes it an excellent contribution not only to the study of the origins of Christianity, but also to illuminating the present ecclesial situation. The present note wishes to enter into dialogue with the work in order to examine some of its most significant aspects in greater depth..

KEYWORDS: Early Church; Ecclesiology; Priesthood.

\section{INTRODUCCIÓN}

La cuestión de los ministerios (instituidos) dentro de la Iglesia es una de gran actualidad en los últimos años. En el pasado Sínodo Extraordinario para la Amazonia a finales de 2019, el tema de la ordenación de los viri probati atrajo gran parte de la atención mediática y tuvo una presencia notable en el debate 
dentro y fuera del aula sinodal. Poco después (abril de 2020),se constituía la segunda comisión para el estudio del diaconado femenino. La anterior había funcionado entre 2016 y 2018. Además, en el Synodalen Weg alemán, todavía en marcha, la ministerialidad de los laicos y su papel dentro de las estructuras jerárquicas eclesiales ocupan un puesto importante en la discusión. Más recientemente, en este mismo año 2021, el Papa Francisco ha escrito dos motu proprio hablando precisamente de los ministerios laicales: Spiritus Domini, donde abre el lectorado y el acolitado a las mujeres, y Antiquum Ministerium, donde instituye oficialmente el ministerio del catequista.

Esta «inquietud institucional» muestra cómo el interés por entender cómo debe ser la Iglesia de nuestro tiempo pasa también por la articulación entre sacerdotes y laicos, su papel en la jerarquía eclesial, y eso incluye necesariamente la comprensión y organización de los ministerios. Esta reflexión es, por tanto, de gran importancia para su renovación siempre necesaria, no sólo en ámbito católico. En este proceso juega un papel fundamental el estudio de los orígenes cristianos, pues las configuraciones de las comunidades primitivas puede iluminar el verdadero sentido del ministerio dentro de la Iglesia. Esto es, precisamente, lo que se propone el profesor Romano Penna en su reciente monografía Un solo corpo. Laicità e sacerdozio nel cristianesimo delle origini, convencido de que en los textos de las primeras generaciones cristianas «se encuentran los fundamentos de la identidad cristiana y eclesial y que deberían constituir el ADN perennemente válido» de la Iglesia ${ }^{1}$.

No se trata, sin embargo, de una tarea fácil. La cuestión del origen de los ministerios cristianos en la forma en la que hoy los conocemos sigue siendo una pregunta abierta en la investigación. Los datos que se conservan de la primera generación son variados y circunstanciales, mientras que los escritos de la tercera generación muestran ya cómo la tríada ministerial «normativa» (episkopos, presbýteros, diákonos) comienza a asentarse. En muchos de los documentos de esta época epískopoi y presbýteroi parecen todavía identificarse, puesto que su separación paulatina hasta establecerse como dos ministerios distintos $-\mathrm{o}$ dos grados de un mismo ministerio- $\mathrm{se}$ producirá a lo largo del siglo II.

Hasta Un solo corpo, la última monografía dedicada a la cuestión es el estudio de Jochen Wagner Die Anfänge des Amtes ${ }^{2}$. Anteriormente, se había

1. R. Penna, Un solo corpo. Laicità e sacerdozio nel cristianesimo delle origini (Frecce 288), Roma 2020, 21.

2. J. Wagner, Die Anfänge des Amtes in der Kirche. Presbyter und Episkopen in der frühchristlichen Literatur (Texte und Arbeiten zum neutestamentlichen Zeitalter 53), Tübingen 2011. 
convertido ya en un clásico The Elders, de R. A. Campbell ${ }^{3}$. Los tres libros se centran especialmente en el ministerio del epískopos-presbiteros, dejando las menciones al diaconado en un segundo plano ${ }^{4}$. Todas ellas examinan el surgimiento del ministerio sacerdotal desde un punto de vista histórico, pero Penna aporta un interesante cambio de perspectiva. El interés principal de su investigación no es tanto el desarrollo concreto de las jerarquías eclesiales, sino cómo se produjo la progresiva diferenciación entre un sacerdocio ministerial que preside la liturgia y administra las comunidades y el resto del Pueblo de Dios, el laicado.

Este cambio de orientación en el estudio aporta una gran originalidad a la obra del italiano, puesto que resitúa la pregunta fuera del marco concreto de la configuración jerárquica de las primeras comunidades. Aunque no deja de lado un minucioso estudio de los textos en su contexto histórico, su punto de vista resitúa la cuestión en el ámbito más amplio de la identidad misma del cristianismo.

La tesis fundamental de Romano Penna es la de la laicidad del cristianismo primitivo. Dado que este término está bastante cargado filosófica, teológica e incluso políticamente en la actualidad, es normal que el autor haya dedicado un capítulo a una clarificación terminológica muy pertinente. Laicidad y laicado, en el sentido en el que se entienden hoy, son dos conceptos desconocidos en la antigüedad. Mientras que en Grecia y Roma era lo perteneciente al «pueblo llano» a diferencia de las clases dirigentes, en el judaísmo de la época -0 , mejor dicho, del siglo II en adelante- $-^{5}$ se refiere a lo profano, no consagrado.

Ninguna de estas dos concepciones de la laicidad podría aplicarse al cristianismo primitivo. Tampoco una idea moderna (política), que entiende «laico» como aquello que se opone a la religión. Más bien, cuando Penna habla de la laicidad del cristianismo primitivo se refiere al hecho de que existe al margen de las estructuras y cánones religiosos (grecorromanas o judías) de

3. R. A. Campbell, The Elders. Seniority within Earliest Christianity, London - New York 1994.

4. Precisamente por su dimensión «no del todo sacerdotal», creo que una reflexión profunda sobre la naturaleza del diaconado es más que pertinente en este proceso de revisión de la ministerialidad de la Iglesia en general y de los laicos en particular. La obra de referencia a este respecto sigue siendo J. N. Collins, Diakonia. Re-interpreting the Ancient Resources, New York 1990. Más recientemente, la obra colectiva B. J. Koet - E. Murphy - E. Ryökas (eds.), Deacons and Diakonia in Early Christianity. The First Two Centuries (Wissenschaftliche Untersuchungen zum Neuen Testament 2. Reihe 479), Tübingen 2018, es una buena muestra del estado actual de la cuestión.

5. Atestiguado en las recensiones de Áquila, Símaco y Teodoción. 
su época. En el sentido más estricto, el cristianismo no nace como una religión. Los primeros pasos del «camino» se parecen más a los de una escuela filosófica de la época. Es más, Penna sostiene que el cristianismo introduce tres conceptos básicos que contribuyen al desarrollo de la idea misma de laicidad: creación, encarnación y escatología ${ }^{6}$. El «revestimiento religioso» de la fe cristiana ocurre en un momento segundo, como una consecuencia lógica de la propia dinámica de la fe.

\section{TRES COORDENADAS LAICAS}

Una parte sustancial de la obra se dedica a demostrar la tesis de la laicidad del cristianismo primitivo a través del examen de tres dimensiones: las personas, el culto y los principios morales y éticos del cristianismo. Dado el tema que centra el estudio, destaca especialmente el primero de los tres aspectos, pues, como el mismo autor afirma, «en las religiones de nuestro mundo mediterráneo ha sido o sigue siendo importante la figura del sacerdote, en relación al que se delinea la posición del laico» ${ }^{7}$.

Pero las otras dos coordenadas son igualmente importantes. Por un lado, la función del sacerdote, al menos en el contexto mediterráneo, está ligada de un modo especial a la ofrenda de sacrificios. Por eso, entender si en el primer cristianismo existía esta concepción aplicada al culto cristiano, especialmente a la eucaristía, es importante para entender la configuración del sacerdocio cristiano. Por otra parte, las religiones de matriz griega (no así el judaísmo) se abstenían de entrar en el terreno moral, que pertenecía al ámbito de las doctrinas filosóficas. El cristianismo, sin embargo, tiene desde el primer momento una fuerte dimensión parenética que debe ser examinada.

\section{a) Los protagonistas del nacimiento de la Iglesia}

El primer paso que da Penna es el de examinar el modo en que se ejerce el sacerdocio tanto en el contexto grecorromano como en el contexto judío. Esto le permite demostrar cómo las figuras más preeminentes de los orígenes del cristianismo contrastan con la praxis sacerdotal del entorno. Excluidos el Bautista y Bernabé ${ }^{8}$, ninguno de los grandes protagonistas del

6. R. Penna, Un solo corpo..., 14.

7. R. Penna, Un solo corpo..., 23.

8. Un factor interesante para futuras investigaciones parte del hecho de que tanto el uno como el otro son presentados como miembros de la casta sacerdotal únicamente en la obra lucana. En la descripción de Juan en el resto de la tradición evangélica -tampoco en Flavio 
nacimiento de la Iglesia pertenece a la casta sacerdotal judía ni ejerce el sacerdocio al estilo grecorromano.

El caso más claro es el de Jesús: judaíta y laico observante. Al mismo tiempo, es tremendamente crítico con los estamentos religiosos de Israel, respecto a los que toma continuamente distancia, especialmente con respecto al Templo. Penna llega a presentarlo, incluso, como un precursor de la separación Iglesia-Estado, a través de la lectura del episodio del pago del impuesto (Mt 22,15-22) .

La laicidad del Maestro es compartida no sólo por los apóstoles y los otros grandes protagonistas del relato neotestamentario, con las excepciones ya mencionadas, sino también por los primeros ministros de las comunidades. Si el objetivo del oficio del sacerdote, tanto en la tradición griega como judía, era obtener la «santidad» o la pax deorum a través de la realización de prácticas rituales que mediaran entre Dios (o los dioses) y la comunidad, no se puede aplicar esta idea a los ministros de las nuevas comunidades ni a la vida cristiana en general. Los testimonios de los escritos neotestamentarios no hablan de «especialistas del culto» que realicen en exclusiva esta función. $\mathrm{Y}$ en ningún caso son llamados hiereîs ${ }^{10}$.

¿Cómo eran, entonces, estos ministros? La investigación histórica acerca de los orígenes de la jerarquía eclesiástica pone de manifiesto que en la primera generación la configuración ministerial de las comunidades era muy plural. Como todo grupo social, se crean rápidamente unas estructuras, pero, a juzgar por la diversidad terminológica que emerge de las cartas paulinas, seguramente esta estuviera todavía in fieri o, incluso, podrían ser distintas de comunidad en comunidad, muy marcadas por su contexto y por la proveniencia social de los cristianos de cada ciudad.

Penna recorre las páginas del Nuevo Testamento, especialmente del epistolario paulino, para entender cómo se organizaban las primeras asambleas cristianas. En su presentación, sin embargo, aparecen dos límites:

-El primero es que presenta el material de modo «geográfico», comenzando por Jerusalén y Antioquía y terminando en las comunidades griegas, dando un salto final al retrato ministerial de las Pastorales. Esta forma de exponer la cuestión dificulta seguir el desarrollo cronológico concreto del nacimiento de

Josefo- no aparece presentado como hijo de un sacerdote. La caracterización de Bernabé como levita es exclusiva de Hechos y no se le menciona como tal en el corpus paulinum ni en la Epístola de Bernabé.

9. R. Penna, Un solo corpo..., 59-60.

10. Salvo el excepcionalísimo caso de Cristo en Hebreos. El desarrollo de la figura de Jesús como mediador-sacerdote en Hebreos se aborda más adelante en la obra. 
los ministerios. Aunque Hechos -la fuente principal para las comunidades de Jerusalén y Antioquía-contiene datos de inmenso valor histórico, estos vienen tamizados por la visión eclesial de Lucas, un autor de la tercera generación.

-El segundo (y principal) obstáculo en el estudio es que se limita prácticamente al estudio de los textos neotestamentarios vinculados principalmente a la tradición paulina. Otros escritos como Mateo o los escritos joánicos, aún cuando pudieran servir para iluminar en cierto modo las estructuras de las comunidades de Antioquía o Éfeso, reciben poca o nula atención. Pero más importante aún es el hecho de que los textos de los padres apostólicos, donde la cuestión del ministerio o del culto adquieren en ocasiones especial relevancia, son usados únicamente para iluminar los textos del Nuevo Testamento. No se habla de Primera Clemente al estudiar la comunidad corintia, ni de las cartas de Ignacio o de la Didaché al tratar Antioquía ${ }^{11}$. Este hecho es sorprendente en la medida en que, precisamente por haber sido escritos en la misma época y poner en primer plano la cuestión central de la investigación, merecerían un análisis paralelo al de los escritos canónicos.

Así pues, Penna se centra en los documentos neotestamentarios de la tradición paulina y pone de manifiesto la diversidad que existía. Macdonald atribuye esto a que posiblemente Pablo concedía mucha libertada a sus comunidades a la hora de tomar decisiones en su funcionamiento interno ${ }^{12}$. Esto se refleja en el tan variado vocabulario que recoge el epistolario paulino, en el que apenas se repiten unos pocos términos a la hora de referirse a los ministros, independientemente de si estos eran hombres o mujeres. Muy probablemente, los cristianos adoptaron estructuras organizativas imitando formas sociales del entorno dependiendo del lugar en el que estaban y del origen concreto de cada una de las asambleas locales. Es clásica la tesis de Meeks proponiendo cuatro modelos con los que comparar las comunidades paulinas primitivas: familia, asociaciones voluntarias, sinagoga y escuelas filosóficas ${ }^{13}$. De estos modelos, Penna descarta la sinagoga, al menos en lo referente a las comunidades paulinas ${ }^{14}$.

11. Sorprende el hecho especialmente de estos dos últimos escritos, especialmente en el apartado que Penna dedica a la comunidad de Antioquía, pues es un corpus de textos donde las cuestiones relacionadas con el ministerio y el culto tienen una especial importancia.

12. M. Y. Macdonald, Las comunidades paulinas. Estudio socio-histórico de la institucionalización en los escritos paulinos y deutero-paulinos (Biblioteca de Estudios Bíblicos 78), Salamanca 1994, 84-85.

13. W. A. Meeks, Los primeros cristianos urbanos. El mundo social del apóstol Pablo (Biblioteca de Estudios Bíblicos 64), Salamanca 1988, 132-148.

14. R. Penna, Un solo corpo..., 99. 
Durante años, el modelo predominante a la hora de considerar la formación de las comunidades ha sido el del núcleo familiar. El hecho de que la tradición neotestamentaria hable abundantemente de las casas como lugar de reunión (Hch 2,$46 ; 5,42 ; 20,20$, por centrarnos en Hechos) y también de conversiones «familiares» (Hch 16,15.34; 18,8) parece avalar la hipótesis de que los grupos cristianos se constituían en torno a esta institución.

Pero, al mismo tiempo, también se presentan otros puntos de reunión como el lugar de oración de Filipos (Hch 16,13.16) y la escuela de Tirano (Hch 19,9). A respecto de esto, otro punto que ha entrado en discusión en los últimos años es el de la «exclusividad» de la casa como lugar de culto de los primeros cristianos. Ciertamente, Pablo y Lucas se refieren a las oíkoi como lugares privilegiados de las comunidades, pero estudios recientes plantean la hipótesis de que quizás el uso de la casa como lugar de reunión no estaba tan extendido o no era tan exclusivo como se ha querido plantear ${ }^{15}$. Penna, en cualquier caso, asume plenamente la hipótesis doméstica tanto en su descripción de la estructura organizativa como en la del culto.

En mi opinión, el modelo familiar aplicado a las comunidades paulinas es más bien punto de llegada en la tradición. Aparece claramente en las Pastorales, pero en los escritos más antiguos tiene más de metáfora del ministerio paulino - es decir, Pablo se presenta como padre de la comunidad- ${ }^{16}$ que de descripción de la estructura concreta de las asambleas cristianas. Por otro lado, en los últimos años, la literatura que se esfuerza en iluminar la problemática de las comunidades de la esfera paulina a partir de los numerosos datos que se poseen respecto a las asociaciones voluntarias es creciente y ha aportado bastantes frutos a la investigación sobre los orígenes del cristianismo ${ }^{17}$.

Posiblemente, el desarrollo de los ministerios entre la primera y la tercera generación se haya producido precisamente a través de este diálogo

15. Sobre todo, E. Adams, The Earliest Christian Meeting Places. Almost Exclusively Houses? (Library of New Testament Studies 450), London - New York 2013 311-328; S. Heid, Altar und Kirche. Prinzipien christlicher Liturgie, Regensburg 2019 69-160, esp. 69-85. Tanto Heid como Adams centran su mirada en las reuniones cristianas, señalan la ambigüedad del término oíkoi y la expresión hē kat'oîkon ekklēsía y aluden la falta de pruebas arqueológicas como criterios para sostener la idea de las comunidades domésticas. En su refutación subyace, además, una crítica a un cierto tipo de eclesiología que se construye sobre una visión romántica de estas comunidades domésticas y del cristianismo primitivo (S. Heid, Altar und Kirche..., 69).

16. D. Villalón Villalón, «Pablo de Tarso, el padre de la comunidad. Autoridad apostólica y modelo paterno-filial», Familia 34 (2007) 43-79

17. Como monografía destaca especialmente J. S. Kloppenborg, Christ's Associations. Connecting and Belonging in the Ancient City, New Haven - London 2019. 
entre ambos modelos. Es probable que los cristianos del ámbito paulino se comprendieran a sí mismos y sus comunidades a la luz de asociaciones que existían en su entorno. Pero también es cierto que existe un movimiento corrector por parte de los autores de esta misma tradición que pretende superar estos modelos que daban lugar a cierta fragilidad ${ }^{18}$. Dada la comprensión que Pablo tiene de su propio ministerio como paternidad, el modelo doméstico termina teniendo éxito con la reelaboración de la memoria del apóstol.

También es muy interesante el paralelo entre el cristianismo y las escuelas filosóficas. No en vano, Pablo es presentado en Hechos entre filósofos a su llegada a Atenas $($ Hch 17,18) y la tradición apócrifa paulina ha incluso compuesto un epistolario entre el apóstol y Séneca. Pero, sobre todo, porque autores cristianos y no cristianos a lo largo de toda la antigüedad señalan la cercanía entre las comunidades y las escuelas filosóficas ${ }^{19}$.

Uno de los datos teológicos más importantes se enuncia en respuesta a esta diversidad y a la fragilidad que podía derivarse de ellas. Ya en tiempos de Pablo se inicia una reflexión sobre este tema que intenta orientar la situación. Como señala Penna, el discurso sobre los carismas, sobre todo en $1 \mathrm{Co}$, recuerda que la diversidad de formas tiene un principio común, el Espíritu, y un fin común, la edificación de la comunidad ${ }^{20}$. La tradición deuteropaulina ve en estos dones un nuevo modo de presencia de Cristo (cf. 4,8). Finalmente, las Pastorales suponen la «institucionalización» y ritualización del carisma, para protegerse de las amenazas propias de esta generación, especialmente los falsos doctores.

La doctrina de los carismas y, en general, la afirmación de que los ministerios eclesiales tienen su origen en la esfera divina, como un don a la Iglesia, y no en el ámbito humano fue seguramente respuesta a las aspiraciones de algunos miembros de la comunidad que ambicionaban los primeros puestos ${ }^{21}$.

A pesar de que en la época de las Pastorales aparece ya como casi asentada la tríada diákonos-presbýteros-epískopos todavía no se puede hablar de sacerdocio propiamente dicho. Se trata todavía, a juicio de Penna, de ministerios laicos, si bien en esta institucionalización -especialmente a través de la imposición de manos, aunque este término es usado también en el ámbito

18. J. Harrison, «Paul's House Churches and the Cultic Associations», The Reformed Theological Review 58 (1999) 31-47.

19. R. Penna, Un solo corpo...101-102.

20. R. Penna, Un solo corpo..., 63-64.

21. J. Harrison, «Paul's House Churches...», 45-47. 
civil para la designación de cargos como el de embajador $-^{22}$ se pueden entrever ya los primeros pasos hacia la aparición del sacerdocio como tal dentro de la Iglesia.

\section{b) El culto de los primeros cristianos}

La segunda coordenada sobre la que Penna asienta la laicidad del cristianismo naciente es, como se decía antes, el culto. Los textos neotestamentarios y patrísticos revelan cómo la vida de las asambleas cristianas difiere sustancialmente de la vida religiosa de su entorno. Cierto, el libro de los Hechos indica una cercanía de la comunidad de Jerusalén con el Templo, pero siempre también desde una cierta distancia crítica similar a la que la tradición evangélica señala de Jesús. En modo paralelo, la polémica de 1Co 8-10 sobre los idolotitos refleja la separación que existe entre la comunidad cristiana de la ciudad aquea y los sacrificios a los dioses griegos.

El lenguaje cultual de los primeros cristianos desconoce, de hecho, la palabra sacrificio. Los ritos de iniciación (bautismo) y de pertenencia (eucaristía) de estas generaciones de cristianos no son para nada semejantes a los de las religiones circundantes. Aunque existen ritos religiosos de purificación con agua tanto en el ámbito cristiano como en el judío, no tienen el mismo valor iniciático que el bautismo cristiano.

En cuanto a la eucaristía, no se utiliza en el vocabulario de los primeros cristianos el término sacrificio asociado al culto. Más bien se desarrolla como los sympósia de los filósofos griegos. Sorprende que, por el uso de la Escritura que el propio Penna señala como distintivo del cristianismo con respecto a los banquetes filosóficos ${ }^{23}$, no se haga mención alguna del culto sinagogal, también «laico» en los términos en que se maneja el vocablo en la obra, donde la lectura y explicación de la Escritura tiene un papel central ${ }^{24}$.

Por otro lado, los lugares de reunión de la comunidad no son templos sino que, de hecho, no existen de hecho lugares de culto «oficiales» para las

22. J. S. Kloppenborg, Christ's Associations..., 293. Es muy sugerente el hecho de que Ignacio use jeirotonéo hasta dos veces en conexión con el oficio del embajador (presbeía IgFil 10,1; theopresbutếs IgSmir 11,2), que eran siempre elegidos por votación. En IgFil 10,1 quien debe ser elegido es un diákonos.

23. R. Penna, Un solo corpo..., 109.

24. Esto no representaría una relación genética entre sinagoga y comunidad cristiana que ha sido rechazada repetidamente en las últimas décadas (R. A. Campbell, The Elders..., 44-54, 111-114; J. Wagner, Die Anfänge des Amtes...,56-64, esp. 63-64), pero sí cómo en el desarrollo histórico del cristianismo se amalgaman elementos del contexto griego y de la tradición judía. 
primeras asambleas puesto que no imitan las formas religiosas de su entorno. Independientemente de la discusión antes planteada acerca de la casa como lugar de culto, lo cierto es que uno de los signos definitorios del sacerdocio antiguo era su vinculación a alguna clase de recinto sacro, y este no es el caso de las comunidades cristianas ${ }^{25}$.

\section{c) Una moral laica}

El tercer dato importante para sostener la laicidad del origen de la Iglesia es la de la moral. Romano Penna pone en valor cómo el cristianismo, ya desde Pablo, asume valores éticos y filosóficos propios de escuelas de pensamiento de su entorno. La vida moral es una manifestación concreta de la $\mathrm{fe}$, pero esta se ejercita desde la libertad de conciencia que el creyente tiene a través de su relación en Cristo. No está vinculada a ningún tipo de ritualidad religiosa que justifica.

\section{HACIA UN SACERDOCIO CRISTIANO}

A pesar de los límites antes descritos, el estudio histórico que Penna realiza en el tercer capítulo de la obra es muy iluminador y establece suficientemente la dimensión laica del primer cristianismo. Lo cierto es que, como demuestran estos datos y los testimonios patrísticos, hasta finales del siglo II no existe una distinción clara entre laicos y sacerdotes dentro de la Iglesia. ¿Cómo surge, entonces, esta diferenciación entre unos y otros hoy en día tan asentada en nuestras comunidades? A la progresiva aparición del sacerdocio cristiano se dedica el último capítulo de la obra.

Existen tres pasos teológicos fundamentales que contribuyen a esta evolución. El primero que menciona Penna es el desarrollo de la imagen de Cristo como sacerdote, que va ligada a la concepción de su muerte como

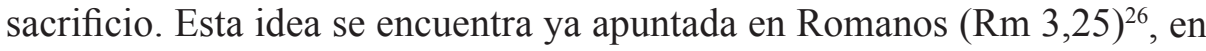
el deuteropaulinismo (Ef 5,2) y en la tradición joánica (1Jn 2,2), pero donde alcanza su mayor esplendor es en la Carta a los hebreos. Afirmar el sacerdocio de Cristo en una nueva clave y en oposición al sacerdocio levítico es, evidentemente, un primer paso que favorecerá la aparición de una clase sacerdotal cristiana.

25. R. Penna, Un solo corpo..., 96.

26. Esto a pesar de que el propio Pablo histórico evita cualquier uso de terminología cultual asociada a Jesús (R. Penna, Un solo corpo... 175-177). 
El segundo desarrollo a nivel teológico es el del sacerdocio común de los fieles. Para Penna esto es consecuencia de la afirmación del sacerdocio de $\mathrm{Cristo}^{27}$, pero realmente esto no puede deducirse de Hebreos y se afirma en escritos (y contextos) donde no se está hablando de esta idea y Penna no llega a demostrar el vínculo entre ambas. Heredando temas veterotestamentarios, la Primera Carta de Pedro (esp. 1Pe 2,4-5.9) afirma que toda la Iglesia es pueblo sacerdotal en su conjunto. Sobre una base similar del Antiguo Testamento, la tradición joánica, en el Apocalipsis afirma que cada cristiano es individualmente un sacerdote (Ap 1,6; 5,10; 20,6). Pablo usa, de hecho, lenguaje cultual y religioso para referirse a la vida común de los fieles ${ }^{28}$.

Un último punto en el que Penna ve los antecedentes teológicos a la aparición de una clase sacerdotal cristiana está en cómo habla Pablo de su ministerio en términos cultuales. El estudio que el autor hace en esta sección es especialmente interesante y muestra cómo ya en la primera generación el apóstol desarrolló una comprensión «cuasi-litúrgica» de su ministerio, del que habla en términos que se acercan al lenguaje sacral y cultual ${ }^{29}$. No se trata de un culto religioso al uso, sino que el anuncio del evangelio se convierte en este servicio sacerdotal.

Ciertamente, la comprensión de Cristo como un sacerdote distinto que propone Hebreos es fundamental en el desarrollo de una imagen cristiana del sacerdocio. Si el discípulo imita a su maestro, el hecho de que Cristo venga considerado como sacerdote tiene importancia teológica. Pero, aún así, el discurso de Hebreos es cristológico y soteriológico y, cuando habla de los líderes eclesiales, no aplica las consecuencias de lo expuesto anteriormente. Lo realmente importante -especialmente teniendo en cuenta que la exposición de Penna se ha centrado de manera particular en la tradición paulina- es la reutilización de la terminología cristiana para la vida común y espiritual de las comunidades y el ministerio de la palabra. Lo es, sobre todo, porque gran parte de la reflexión teológica sobre el ministerio en las etapas posteriores del paulinismo se construye a través de la reelaboración de la memoria del apóstol. En este punto, resulta decisivo que el propio apóstol haya hablado de su propia actividad de predicación como de un sacerdocio -aún sin llamarlo así explícitamente-.

Junto a estas dos ideas, desde el punto de vista histórico, lo que juega un papel fundamental en la progresiva distinción entre sacerdotes y laicos es la

27. R. Penna, Un solo corpo..., 177.

28. R. Penna, Un solo corpo ..., 189-200.

29. R. Penna, Un solo corpo..., 180-189 
especialización del culto. Si bien las fuentes más antiguas no hablan específicamente de quién preside la liturgia, hacia mediados del siglo II aparece de modo cada vez más claro una clase sacerdotal distinta. De un modo más superficial que el examen previo sobre las fuentes neotestamentarias, Penna va exponiendo sobre la base de testimonios de los Padres e incluso de concilios modernos como Trento y el Vaticano II cómo esta separación aparece progresivamente en cuatro ámbitos: el lenguaje, el rito (de ordenación), la vestimenta y el comportamiento social (el celibato).

\section{CONCLUSIÓN}

En conjunto, Un solo corpo es una lectura muy sugerente y estimulante a la hora de indagar sobre los orígenes de la ministerialidad eclesial. Su gran mérito es, seguramente, el de haber dado un paso atrás y haber encuadrado la reflexión sobre el nacimiento del sacerdocio cristiano en el conjunto más amplio de la identidad de las comunidades y del sacerdocio común de los fieles. No nacen como una «casta aparte» o como un «oficio especializado» sino que surgen como la manifestación concreta de algo que atañe a toda la Iglesia.

Este punto de vista que adopta Romano Penna es especialmente sugerente, pues desliga la cuestión de un simple examen histórico acerca de la jerarquía -aun siendo un buen estudio- y, también, la separa de una mirada «clericalista». Sólo en las últimas diez páginas de la obra, de hecho, se habla de cómo el sacerdocio se convirtió en un estamento aparte dentro de la Iglesia, hasta entonces, se ha hablado de la ministerialidad en la Iglesia como una consecuencia normal de su estar en el mundo y de su misión de anunciar el Evangelio.

Esto hace que la reflexión sobre esta cuestión sea de inmensa actualidad en la Iglesia en el contexto presentado al inicio de esta nota. Y, si bien existen desarrollos posteriores en era patrística que merecen la pena ser estudiados y que apenas han recibido atención en el libro, las bases que sienta Romano Penna en Un solo corpo son tremendamente útiles y estimulantes a la hora de entender qué es y cómo se debe entender el sacerdocio en la Iglesia y la articulación laicos-sacerdotes dentro del Pueblo de Dios. 


\section{BIBLIOGRAFÍA CITADA}

Adams, E., The Earliest Christian Meeting Places. Almost Exclusively Houses? (Library of New Testament Studies 450), London - New York 2013

Campbell, R. A., The Elders. Seniority within Earliest Christianity, London - New York 1994.

Collins, J. N., Diakonia. Re-interpreting the Ancient Resources, New York 1990.

Harrison, J., «Paul's House Churches and the Cultic Associations», The Reformed Theological Review 58 (1999) 31-47.

Heid, S., Altar und Kirche. Prinzipien christlicher Liturgie, Regensburg 2019.

Kloppenborg, J. S., Christ's Associations. Connecting and Belonging in the Ancient City, New Haven - London 2019.

Koet, B. J. - E. Murphy - E. Ryökas (eds.), Deacons and Diakonia in Early Christianity. The First Two Centuries (Wissenschaftliche Untersuchungen zum Neuen Testament 2. Reihe 479), Tübingen 2018.

Macdonald, M. Y., Las comunidades paulinas. Estudio socio-histórico de la institucionalización en los escritos paulinos y deutero-paulinos (Biblioteca de Estudios Bíblicos 78), Salamanca 1994.

Meeks, W. A., Los primeros cristianos urbanos. El mundo social del apóstol Pablo (Biblioteca de Estudios Bíblicos 64), Salamanca 1988, 132.

Penna, R., Un solo corpo. Laicità e sacerdozio nel cristianesimo delle origini (Frecce 288), Roma 2020.

Villalón Villalón, D., «Pablo de Tarso, el padre de la comunidad. Autoridad apostólica y modelo paterno-filial», Familia 34 (2007) 43-79.

Wagner, J., Die Anfänge des Amtes in der Kirche. Presbyter und Episkopen in der frühchristlichen Literatur (Texte und Arbeiten zum neutestamentlichen Zeitalter 53), Tübingen 2011. 